\title{
ANálisis del hashtaG \#MEQUEdoEnCASA: LA CONVERSACIÓN DIGITAL POR TWITTER ANTE LA EMERGENCIA PRODUCIDA POR LA COVID-19
}

\author{
An Analysis of the Hashtag \#MeQuedoEnCasa: Digital Conversations \\ IN TWITTER ${ }^{\circ}$ AMID THE EMERGENCY PRODUCED BY COVID-19 \\ UNe ANALYSE DU haShTAg \#MEQUEDoEnCASA : LA CONVERSATION NUMÉRIQUE \\ SUR TWITTER ${ }^{\circledast}$ FACE À LA CRISE SANITAIre LIÉE À LA COVID-19
}

\section{Cristina Vela Delfa}

Doctora en Ciencias del Lenguaje y la Literatura, Universidad Complutense de Madrid, España. Profesora contratada doctora, Facultad de Ciencias Sociales Jurídicas y de la Comunicación, Universidad de Valladolid, España. cristina.vela@uva.es

https://orcid.

org/0000-0002-4915-5260

\section{Lucía Cantamutto}

Doctora en Letras, Universidad Nacional del Sur, Argentina. Investigadora, Universidad Nacional de Río Negro, Sede Atlántica. Centro Interdisciplinario de Estudios sobre Derecho, Inclusión y Sociedad (CIEDIS) / Consejo Nacional de Investigaciones Científicas y Técnicas (CONICET), Argentina.

luciacantamutto@gmail.com https://orcid. org/0000-0001-5868-7608

Marian Núñez-Cansado Doctora en Ciencias de la Información, Universidad Complutense de Madrid, España.

\section{RESUMEN}

La crisis sanitaria de la COVID-19 vino acompañada de medidas de aislamiento, entre las que se encontraba el confinamiento domiciliario, que provocaron múltiples reacciones en las redes sociales. El objetivo de este artículo consiste en analizar la conversación digital observada en Twitter, en torno al hashtag \#MeQuedoEnCasa, en el periodo comprendido entre el 20 y el 27 de marzo de 2020. El estudio parte de una metodología mixta, en la que se combinan técnicas de análisis del social media mining con estrategias cualitativas propias del análisis lingüístico. Desde el punto de vista teórico, nos apoyamos en conceptos de las teorías del encuadre y de la valoración. Los resultados apuntan al enmarque positivo del confinamiento, a través de rasgos semióticos de distinto nivel: léxico, semántico y pragmático. Las cuentas más influyentes inclinaron su producción discursiva hacia la polaridad positiva. El análisis empírico permite concluir que el encuadre discursivo de esta conversación digital combina dos ejes semánticos (colectividad y salud), dos ejes enunciativos (aquí y ahora) y un eje emocional, lo que implica que hashtags como \#MeQuedoEnCasa funcionan como señas de identidad social, como marcas de anclaje enunciativo y como instrumentos para fomentar la responsabilidad del individuo desde valores positivos.

Palabras clave: COvid-19; teoría del encuadre; análisis lexicométrico; redes sociales; teoría de la valoración; Twitter ${ }^{\circledR}$; conversaciones digitales.

\section{Abstract}

The Covid-19 sanitary crisis came along isolation measures, among which was the lockdown that triggered multiple responses in social media. This article aims to examine digital discussions that took place through the hashtag \#MeQuedoEnCasa (Spanish for "I'm Staying Home"), between the $20^{\text {th }}$ and $27^{\text {th }}$ of March 2020. The study is set around a mixed methodology in which social

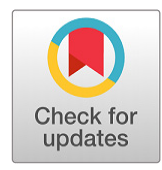

Recibido: 2020-09-14 / Aceptado: 2020-11-20 / Publicado: 2021-05-05

https://doi.org/10.17533/udea.ikala.v26n2a08 
Profesora contratada doctora, Facultad de Ciencias Sociales Jurídicas y de la Comunicación, Universidad de Valladolid, España. marian@hmca.uva.es https://orcid. org/0000-0002-6658-3996 media mining techniques are combined with qualitative strategies, inherent to discourse analysis. From a theoretical point of view, we draw on Framing and Appraisal theories. Our results point to a positive framing of the lockdown through semiotic traits at different levels: lexical, semantic and pragmatic. The most influential accounts bent their discursive production towards the positive polarity. The empirical analysis allows us to conclude that the discursive framework of this digital conversation combines two semantic axes (community and health), two enunciative axes (here and now) and one emotional axis, which implies that hashtags such as \#MeQuedoEnCasa works as signs of social identity, enunciative indexing marks, and instruments to promote individual responsibility from positive values.

Keywords: COVID-19; framing theory; linguistic analysis; social media; appraisal theory; Twitter; digital conversations.

\section{RÉSUMÉ}

La crise sanitaire provoquée par la COVID-19 s'est accompagnée de mesures d'isolement, parmi lesquelles la détention à domicile, qui a provoqué de multiples réactions sur les réseaux sociaux. L'objectif de cet article est d'analyser la conversation numérique sur Twitter, autour du hashtag \#MeQuedoEnCasa (\#JeResteChezMoi, en espagnol), dans la période du 20 jusqu'au 27 mars 2020. L'étude est basée sur une méthodologie mixte qui combine des techniques d'exploration des médias sociaux avec des stratégies qualitatives typiques de l'analyse du discours. D'un point de vue théorique, nous nous appuyons sur des concepts issus de la théorie du cadrage et de l'évaluation. Les résultats indiquent un cadrage positif du confinement à travers des caractéristiques sémiotiques à différents niveaux : lexical, sémantique et pragmatique. Les comptes les plus influents ont incliné leur production discursive vers la polarité positive. L'analyse empirique permet de conclure que le cadrage discursif de cette conversation numérique combine deux axes sémantiques (collectivité et santé), deux axes énonciatifs (ici et maintenant) et un axe émotionnel, ce qui implique que les hashtags comme \#MeQuedoEnCasa fonctionnent comme des marques d'identité sociale, des marques d'ancrage énonciative et des instruments pour promouvoir la responsabilité de l'individu sur la base de valeurs positives.

Mots-clés : Covid-19; théorie du cadrage ; théorie de l'évaluation ; Twitter ${ }^{\circ}$; réseaux sociaux; 


\section{Introducción}

El 14 de marzo se declara en España el estado de alarma sanitaria, por la amenaza de la covid-19, que imponía medidas severas de aislamiento para la ciudadanía, entre las que se incluía la permanencia obligatoria en el domicilio. Poco a poco, otros países hispanohablantes toman medidas similares, como, por ejemplo, el impuesto por la orden de "Aislamiento social, preventivo y obligatorio" en Argentina (2020).

Los temas tratados en Twitter ${ }^{\circ}$, como termómetro de la sociedad, evidencian el impacto que estas medidas tuvieron sobre la población y, como era de prever, muchos de los enunciados producidos en este periodo abordaron cuestiones relacionadas con el coronavirus y sus consecuencias. Así, según el informe publicado por la empresa Epsilon Technologies (2020), en el periodo comprendido entre el 1 de febrero y el 22 de marzo de 2020, la etiqueta (hashtag) \#MeQuedoEnCasa, o su forma alternativa \#YoMeQuedoEnCasa, tuvo 1040142 menciones entre Twitter $^{\circ}$ e Instagram, mientras que \#Coronavirus o \#Covid19 tuvieron, respectivamente, 1768599 y 1503778.

El objetivo de este trabajo es investigar los procedimientos de representación discursiva en torno al confinamiento domiciliario en relación con la crisis de la covid-19, a partir del análisis de un corpus conformado por 9712 tuits que fueron marcados con la etiqueta \#MeQuedoEnCasa, o con su versión alternativa, \#YoMeQuedoEnCasa, entre el 20 y el 27 de marzo de 2020. Buscamos verificar de qué manera la elección de este hashtag determina el encuadre discursivo (Entman, 2008) y opera como atributo sobre el que los sujetos construyen la representación social (Moscovici, 1961) del confinamiento en tanto que experiencia compartida (McCombs, 2006).

La etiqueta \#YoMeQuedoEnCasa convive en el tiempo con otras también relativas a la crisis del coronavirus; pero, a diferencia de aquellas, la formulación de este hashtag no remite directamente a la enfermedad o a la crisis sanitaria, sino a la experiencia del encierro y a la forma en la que se incorpora esta nueva situación a la cotidianidad. Es por ello por lo que \#YoMeQuedoEnCasa concentra su mayor actividad discursiva en los primeros días del estado de alarma. Además, las características de la etiqueta permiten suponer una tendencia hacía la polaridad positiva. Por la manera en que se enuncia, esta etiqueta no solo activaría ciertas representaciones sociales, sino que además determinaría su representación discursiva (Moscovici, 1998).

A continuación, en el siguiente apartado se recoge el marco teórico, con los conceptos que aplicamos en este estudio. Luego, se presentan el diseño metodológico del trabajo y, después, los resultados obtenidos mediante el análisis cuantitativo y el cualitativo. Por último, se incluye una sección en la que se discuten los resultados y se exponen las principales conclusiones.

\section{Marco teórico}

Twitter ${ }^{\circ}$ es una red social de microblogging que permite agrupar la producción discursiva en torno a hashtags sobre los que se articula la conversación digital (Arroyas Langa et al., 2018; Larrondo et al., 2019). Estas etiquetas no solo aglutinan opiniones, sino que también determinan los procesos inferenciales. De hecho, como sostienen Molpeceres Arnáiz y Filardo Lamas (2020),

\section{[...] las redes sociales son reflejo y a la vez medio de construcción de percepciones [...] por su capacidad para realizar distintas funciones sociales y comunica- tivas a la vez, entre las que se encuentran la creación y visibilización de diversos discursos (p. 57).}

En tal sentido, el concepto de encuadre oframing, manejado por Entman (1993), puede ser aplicado con éxito al estudio de la construcción discursiva de los tuits, ya que nos permite relacionar la representación de una experiencia con sus contextos de interacción (Ardèvol-Abreu, 2015).

Desde esta perspectiva, las etiquetas asumen una especial relevancia en la conformación de los marcos de interpretación. El encuadre determina 
la información recogida en un texto y la manera en que esta se organiza, se relaciona y se prioriza. Por eso, en las redes sociales, los hashtags sirven para describir la experiencia concreta o el marco conceptual al que apela el tuit. Pero también se establecen como herramientas de búsqueda, codificadas por la propia plataforma, para identificar la potencial comunidad discursiva.

Precisamente, desde esta dimensión interpersonal es importante reconocer que los hashtags no se generan de forma aislada, sino en relación con otros, con los que interactúan y dialogan (Zeifer, 2020). En tal sentido, conviene recordar que, en Twitter ${ }^{\circ}$, las comunidades se articulan de manera compleja. Acosta y Nevache (2020) refieren cinco posibles arquetipos: 1) grupos polarizados, 2) grupos densos, 3) comunidades agrupadas, 4) redes de difusión y 5) redes de apoyo o soporte. A pesar de que, en los grupos densos o las comunidades agrupadas, pueden manifestarse vínculos estrechos, en la mayoría de las ocasiones estas comunidades se caracterizan por relaciones de baja intensidad con escasa vinculación. Es por ello por lo que, en la línea de lo sostenido por Zappavigna (2011), asumimos que los hashtags funcionan como marcas de afiliación ambiental, determinantes de los procesos de creación y mantenimiento de estas comunidades. Estas etiquetas no solo ligan las intervenciones y permiten a los participantes conocer las nuevas aportaciones de los miembros de la comunidad, sino que también encuadran los mensajes que circulan en ellas (Van Gorp, 2007), a partir de un conjunto de atributos, interpretaciones y actitudes.

Pero ¿cómo se construye esta polaridad? O, dicho en otras palabras, ¿cómo se articula discursivamente esta evaluación emocional? Dado que la expresión de valores es un componente indisociable de todo proceso de comunicación, la evaluación constituye en sí misma una característica dominante del propio lenguaje como sistema y ha recibido, por ello, la atención de lingüistas interesados en distintos campos y formados en diferentes escuelas. Entre todos estos acercamientos, la teoría de la valoración (Martin y White, 2003) appraisal theory, en inglés- constituye, a nuestro modo ver, la propuesta más interesante y productiva para el análisis de la función evaluativa en el lenguaje (Kaplan, 2004).

La teoría de la valoración estudia los recursos lingüísticos empleados por los interlocutores para expresar y negociar determinadas posiciones intersubjetivas en los discursos (White, 2004). Se enmarca dentro de la lingüística sistémico-funcional, como una extensión de la investigación sobre la metafunción interpersonal. Se interesa, en particular, por aquellos recursos destinados a codificar la expresión de la valoración, la actitud y la emoción, elementos fundamentales en el encuadre ideológico de la agenda mediática.

La teoría de la valoración parte de la hipótesis de que ciertos elementos lingüísticos modifican la relación afectiva del hablante con su contenido proposicional en tres dominios posibles: actitud, compromiso y gradación (Moreno Ortiz, 2019).

La actitud hace referencia a los valores que los hablantes comunican en sus textos y a las respuestas emocionales que asocian con los procesos dialógicos, es decir, con la transmisión de una evaluación positiva o negativa respecto algo o alguien. Por su parte, el compromiso remite a los recursos empleados para posicionar la voz del hablante en relación con el contenido de un texto. Por último, la gradación envía a la manera en que los hablantes intensifican o disminuyen la fuerza ilocutiva de sus enunciados (Kaplan, 2004).

Con la expansión de las diferentes técnicas estadísticas aplicadas al ámbito conocido como “análisis de sentimientos", la teoría de la valoración se torna especialmente relevante, al ofrecer un correlato cualitativo, muy bien armado desde el punto de vista lingüístico, para explicar los procedimientos que nos permiten verbalizar nuestras valoraciones intersubjetivas. 


\section{Método}

Nuestra estrategia metodológica ha sido diseñada en tres etapas: en la primera se efectuó la selección y el marcado automático del corpus. En la segunda etapa se procedió al análisis cuantitativo del corpus completo. Por último, se realizó el análisis cualitativo de una muestra reducida del corpus, seleccionada aleatoriamente.

La descarga y compilación del corpus sellevó a cabo mediante una llamada (o descarga automática de tuits) al hashtag \#YoMeQuedoEnCasa, a través de la interfaz de programación de aplicaciones (application programming interface, API) de Twitter. De tal manera que, en el periodo de tiempo comprendido entre el 20 y el 27 de marzo de 2020 , se recuperaron un total de 9712 tuits que contenían esta etiqueta.

Para la selección del corpus no se atendió a la geolocalización, por lo que se abarcaron las intervenciones escritas en español que contenían el hashtag \#YoMeQuedoEnCasa. No obstante, como se confirma por el hecho de que una de las palabras más frecuentes del corpus fuera "España", la mayoría de las publicaciones tratan sobre la situación de este país.

El recorte temporal coincide con una de las fracciones con mayor actividad del hashtag \#MeQuedoEnCasa. Como puede verse en la Figura 1, la actividad de esta etiqueta se concentró en torno a la semana del 20 al 27 de marzo de 2020. Posteriormente, cayó en desuso y tomó mayor protagonismo \#Covid.

En la compilación del corpus se mantuvieron algunas marcas, que permitieron trabajar tres variables: 1) número de seguidores de la cuenta de origen; 2) estatus de la cuenta de origen, diferenciando entre cuentas oficiales y no oficiales, $y$ 3) actividad del tuit, con el número de FAV (favorabilidad, similar a un "me gusta") de cada tuit y sus retuiteos.

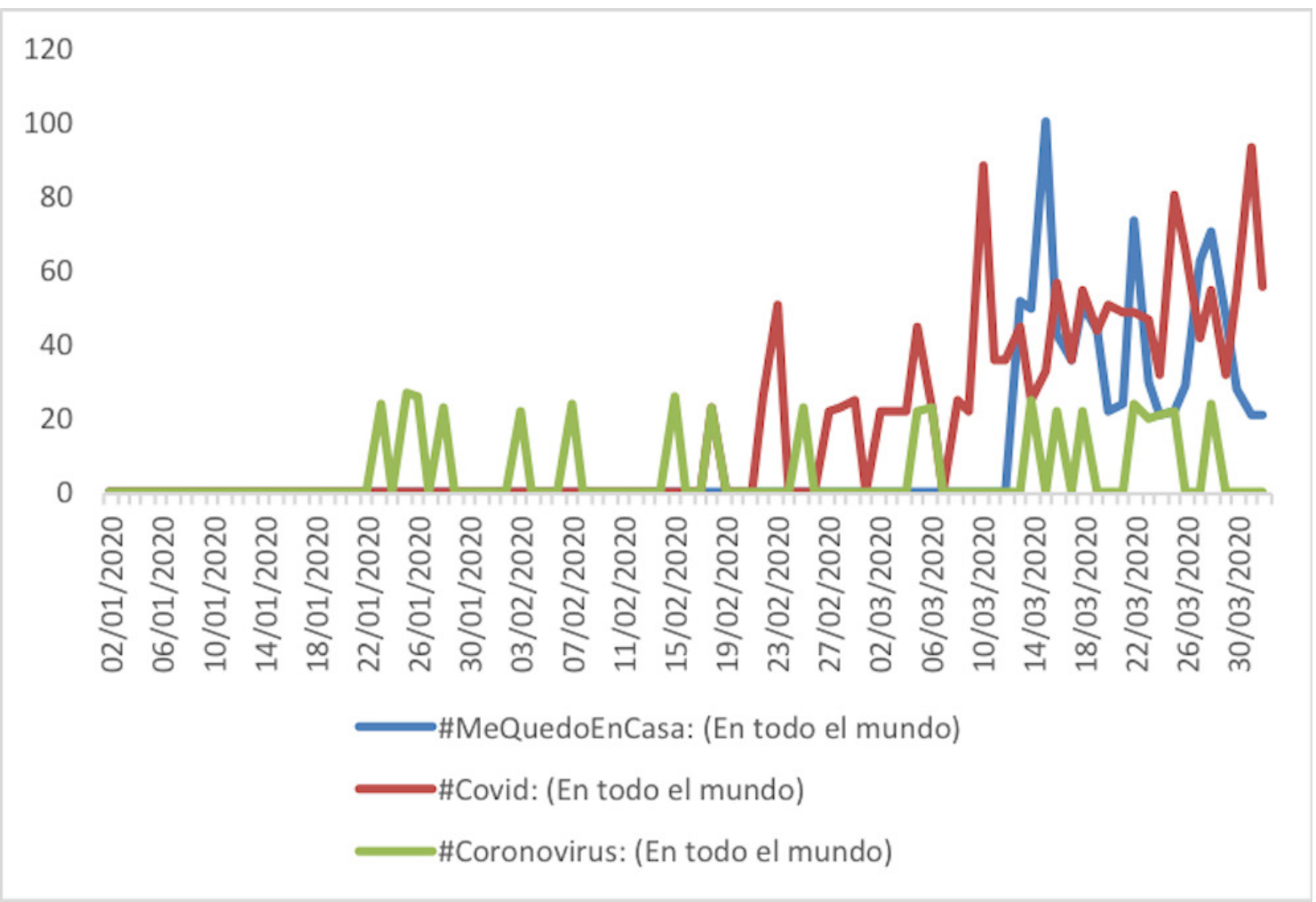

Figura 1 Actividad de hashtags relacionados con la crisis de la covid-19 
En la fase de análisis del corpus se trabajó con la api Natural Language de Google. A través de ella, se procedió a la clasificación de los tuits en función de los criterios de polaridad emocional codificados por la aplicación. De tal forma que cada tuit fue distribuido en una de las siguientes categorías: positivo, negativo o neutro. Asimismo, a cada tuit se le atribuyó un valor relativo, según su polaridad emocional, mediante un puntaje numérico, comprendido entre el $-0,9$ y el 0,9 . De tal suerte que un tuit con valor 0,9 habría de considerarse altamente positivo, mientras que aquel marcado con $-0,9$ sería muy negativo.

El análisis de los datos siguió una estrategia metodológica mixta. Para el cálculo cuantitativo, se volcó el corpus completo en la api Big Query. El resultado se organizó en una planilla de Excel $^{\circ}$ que diferenciaba las siguientes variables: url, texto del tuit, mención, puntaje de polaridad emocional, seguidores, favoritos. Asimismo, los textos de los tuits fueron sometidos a un análisis lexicométrico, por medio de la herramienta AntConc. Se procedió al cálculo de las frecuencias léxicas y a la observación de las principales colocaciones que contenían las palabras más usadas. Además, la muestra de 9172 tuis fue analizada por una función en desarrollo de la aplicación CoDiCE (Cantamutto, et al, 2015), para extraer automáticamente todos los emojis y textos con formato diferente. En esta etapa no se analizaron los enlaces ni las imágenes embebidas.

En la tercera fase se procedió a un cribado manual del corpus, a fin de generar una muestra representativa de 600 tuits, distribuidos de forma equilibrada entre las tres categorías de polaridad. Para ello, en primer lugar, se eliminaron los tuits repetidos, los retuits o tuits sucesivos de una misma cuenta que no presentaran modificaciones sustanciales. En segundo lugar, se seleccionaron 200 tuits diferentes para cada categoría, mediante la función “=ALEATORIO" de Excel".

Por su parte, esta muestra reducida de 600 tuits fue sometida a un análisis cualitativo. Para ello, priorizamos el análisis de algunas categorías léxicas, de ciertas colocaciones y de los emojis.

\section{Resultados}

En esta sección presentamos y discutimos algunos de los principales resultados derivados del rastreo de la etiqueta \#YoMeQuedoEnCasa.

\section{Análisis de la polaridad emocional}

Las aplicaciones para el análisis automático empleadas en este trabajo nos han permitido clasificar los tuits en tres categorías de polaridad - positiva, neutra o negativa-, en función de ciertos rasgos léxicos y de los emojis que se emplean en las publicaciones.

El análisis de los datos apunta cierta tendencia hacía la polaridad positiva. Solo el $12 \%$ de los tuits fueron marcados por la aplicación como representativos de polaridad emocional negativa, mientras que el $38 \%$ fueron considerados emocionalmente positivos. De todos modos, fue la categoría central, la que recoge los tuits emocionalmente neutros, la que experimentó más atribuciones: un $40 \%$ de la muestra.

Como indicamos en el apartado anterior, la atribución de polaridad emocional no se produce de manera discreta, sino que en ella puede explorarse un continuo valorativo que va del 0,9 al $-0,9$. Si observamos la Figura 2, podemos comprobar que la mayoría de los tuits se concentran en el centro, aunque el sesgo se orienta hacia la parte izquierda, es decir, hacia la valoración positiva.

La tendencia positiva de la muestra podría ser explicada por la propia formulación del hashtag, que influye en la orientación emocional de la conversación, es decir, funciona como una estrategia de encuadre discursivo (Gallardo Paúls, 2014). Como apuntábamos en la introducción, respecto a otros hashtags como \#Coronavirus o \#Covid19, la etiqueta \#MeQuedoEnCasa no focaliza en la enfermedad ni en la crisis sanitaria, sino en la idea de confinamiento y de protección, 


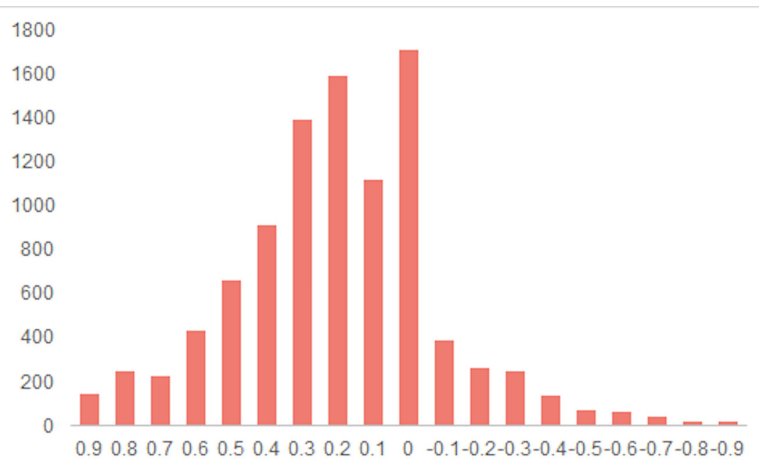

Figura 2 Distribución de los tuits según la atribución emocional proyectada por la aplicación Natural Language de Google

lo que explica el sesgo positivo respecto a los resultados obtenidos en otros estudios (véase Pérez-Dasilva et al., 2020).

La presencia de la primera persona, a través de los pronombres "me" y "yo", \#MeQuedoEnCasa o \#YoMeQuedoEnCasa, verbaliza un sentido de responsabilidad y de elección personal que se proyecta en buena parte de los mensajes posteados. El tuit del Ejemplo 1, marcado con 0,9, ilustra la tendencia fundamental del encuadre conversacional del momento: vivenciar positivamente el confinamiento, mediante propuestas con las que ocupar de manera activa el tiempo.

\section{Ejemplo $1^{1}$}

Música, teatro, cine o visitas virtuales a museos son algunos de los recursos que recopilamos para entretenernos durante estos días de confinamiento https://t. co/xxxxxxxxxx \#QuédateEnCasa \#MeQuedoEnCasa \#Covid19 \#Coronavirus.

También estimamos que el momento de recogida de los datos influye en su orientación emocional. La semana elegida se corresponde con la fase inicial del confinamiento. En España, el estado de alarma

1 Si bien los mensajes producidos en Twitter ${ }^{\circ}$ son públicos, para no favorecer la trazabilidad de los datos y la identificación de los perfiles que produjeron o retuitearon estos tuits hemos anonimizado algunos mensajes y quitado los enlaces que permitieran la identificación de las cuentas que habían producido los enunciados. se declaró el día 14 de marzo, por lo que los ciudadanos españoles habían tenido una semana para acostumbrarse a la situación, pero todavía no sentían el cansancio del encierro prolongado.

Si desglosamos los datos por días, podemos observar la evolución de la polaridad emocional. En los últimos días se recogen menos tuits negativos, por lo que podríamos suponer que los ciudadanos van tomando conciencia de la necesidad del confinamiento. En la Figura 3 podemos ver la evolución por día de la polaridad emocional.

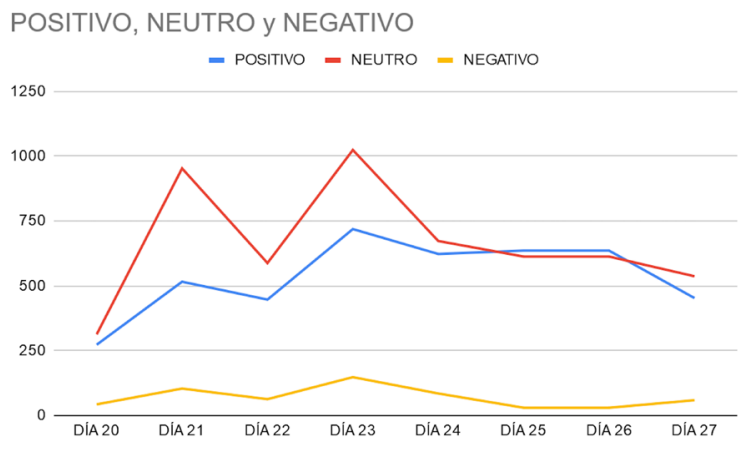

Figura 3 Distribución de lo tuits por día y según su polaridad

Los mayores picos de actividad se concentraron en los días 21 y 23 de marzo, sábado y lunes, respectivamente. El día 20 solo se postearon 629 tuits con la etiqueta, pero el día 21, sábado, la cifra casi se triplicó, con 1573 mensajes, de los cuales solo 43 eran negativos. Se trataba del primer fin de semana de confinamiento y la consigna de quedarse en casa se hizo especialmente relevante.

Muchos de los mensajes compartidos tienen que ver con planes de ocio y propuestas para aprovechar el tiempo en casa, como ilustra el Ejemplo 2.

\section{Ejemplo 2}

La Comunidad de Madrid propone planes virtuales de cultura y turismo. https://t.co/xxxxxxxxxx \#MeQuedoEnCasa \#YoMeQuedoEnMiCasa \#Covid19 https://t.co/Xxxxxxxxxx

Sin embargo, el domingo se tuitearon 1098 tuits, de los cuales 63 fueron negativos. Por su parte, 
el lunes 23 de marzo fue el día con más actividad, con 1821 mensajes, entre los que la herramienta de análisis de sentimientos clasificó 148 como negativos.

Cabría preguntarse qué tienen en común estos mensajes. La mayoría de ellos tratan cuestiones políticas y se relacionan con críticas a ciertas decisiones de tal índole, muchas de ellas presentadas la víspera en una comparecencia del presidente del Gobierno español, como en el Ejemplo 3. Pero también hay otros que muestran sentimientos de cansancio y agotamiento por el encierro, como en el Ejemplo 4.

\section{Ejemplo 3}

Y qué hacen los Jefes de autoridad en la Feria de Madrid sin Mascarillas...\#MeQuedoEnCasa

Ejemplo 4

Esto de estar encerrado en la casa no es para mí

A partir del 24 de marzo, la actividad del hashtag va decayendo progresivamente y el 27 de marzo, viernes, encontramos únicamente 990 registros.

\section{Extensión de los tuits}

A pesar de la consabida restricción de caracteres de los tuits, lo que observamos en nuestro corpus es que la mayoría son extensos. Vale mencionar que algunos mensajes superan el límite permitido de 280 caracteres, porque tienen imágenes embebidas que, al extraer el tuit, se observan como enlace. De hecho, el promedio, es decir, la media aritmética de caracteres empleados, es de 216, mientras que la media para las palabras es de 25. Si, por el contrario, nos fijamos en la moda, observamos que la extensión que más veces se repite en la muestra completa es 109 caracteres y 16 palabras, respectivamente. Resulta reseñable el hecho de que los tuits que se agruparon en la polaridad negativa son más extensos. En la Tabla 1 se recogen los datos desglosados.
Tabla 1 Extensión de palabras y caracteres de los tuits según su polaridad

\begin{tabular}{lllll}
\hline & \multicolumn{2}{c}{ Caracteres } & \multicolumn{2}{c}{ Palabras } \\
\hline Polaridad & Media & Moda & Media & Moda \\
Positivo & 215 & 303 & 24 & 18 \\
Neutro & 192 & 109 & 25 & 16 \\
Negativo & 214 & 309 & 26 & 31 \\
\hline
\end{tabular}

\section{Difusión y circulación de los tuits}

Otro aspecto que indagamos en vistas de comprender cómo se organizó la conversación digital alrededor del tópico \#YoMeQuedoEnCasa fue el nivel de circulación de tuits. Nos interesaba ver si el intercambio se había realizado a partir de muchos tuits diferentes, es decir, que no se habían retuiteado o publicado previamente, o si, por el contrario, una buena parte se correspondían con enunciados duplicados, bien por el mecanismo de retuit o bien por la publicación continuada del mismo texto en diferentes intervenciones.

Los resultados de esta observación fueron los siguientes: del total de tuits producidos en el periodo analizado, solo se contabilizaron 3971 tuits diferentes, el resto fueron retuits o tuits que repetían el mismo texto. Para llevar a cabo los cálculos de repetición y el cribado de mensajes duplicados se tuvieron en cuenta las posibles modificaciones menores a las que podían ser sometidos los textos: cambios de formato, signos de puntuación añadidos, etc.

Como mencionamos en la introducción, en Twitter ${ }^{\circ}$ la dimensión interpersonal del lenguaje y la intertextualidad discursiva constituyen el eje vertebrador del proceso de interacción y, en tal sentido, la propia arquitectura de la interfaz ha ido incorporando elementos en tal dirección, por ejemplo, el hipervínculo apelativo (CautínEpifani, 2015) o los propios hashtags, en tanto que ejes temáticos para enlazar individuos con intereses comunes. El hipervínculo apelativo, conocido en el lenguaje de la red con el término "mención", 
sirve para llamar la atención de la audiencia, así como para manifestar la adhesión a cierto contenido proposicional.

En tal sentido, tanto los hashtags como las menciones actúan como una suerte de altavoces que aumentan la audiencia potencial de un mensaje. Asimismo, asumen un importante valor para la construcción ideológica. De tal suerte que no solo se permite generar una audiencia, sino también entablar relaciones desde la dimensión interpersonal de la comunidad. Además, estos vínculos tienen un efecto intertextual, fundamental en una red social como Twitter ${ }^{\circ}$, marcada por la restricción de caracteres. En síntesis, mediante estas etiquetas,
Twitter $^{\oplus}$ da cuenta de las tres metafunciones básicas que, según la lingüística sistémico-funcional, manifiesta el lenguaje: una función ideacional, para representar la experiencia; una función interpersonal, para negociar las relaciones; y una función textual, para organizar la información.

En la Tabla 2 se recogen los cinco tuits con mayor nivel de circulación. Se incluye también el valor acumulado de las veces que cada tuit fue marcado como favorito.

Observamos que los tuits de la Tabla 2 abordan temáticas muy diferentes, que van desde el fútbol y las consecuencias del confinamiento en la liga

Tabla 2 Grado de circulación de los tuits a partir de la cantidad de retuits y FAV

\begin{tabular}{|c|c|c|c|}
\hline & $\begin{array}{l}\text { Cantidad } \\
\text { de retuits }\end{array}$ & $\begin{array}{l}\text { Cantidad } \\
\text { de fav } \\
\text { (suma) }\end{array}$ & Polaridad \\
\hline $\begin{array}{l}\text { Muchos nos dan ánimo, ánimo? De eso nos sobra somos cántabros y del Racing. } \\
\text { \#MeQuedoEnCasa \#AplausoSanitario }\end{array}$ & 280 & 746 & Neutro \\
\hline $\begin{array}{l}\text { Sabemos que hablar con los niños y niñas más pequeños de \#covid-19 no es fácil. } \\
\text { Y si comenzamos con: "Los coronavirus son un tipo de que los Ilamaron así porque parece } \\
\text { que tienen } \\
\text { Guía para la familias } \\
\text { \#LAVATELASMANOS \#MeQuedoEnCasa https://t.co/xxxxxxxxxx }\end{array}$ & 109 & 137 & Neutro \\
\hline $\begin{array}{l}\text { Nada más verlo, causa pavor. } 2 \\
\text { En manos de un psicópata, egocéntrico, narcisista, traidor a \#España estamos. } \\
\text { Ha dividido la NACIÓN y nos está M A T A N D } 0 \\
\text { MÁS DE } 1000 \text { MUERTES POR SU IRRESPONSABILIDAD. } \\
\text { \#PedroSánchezDimisión } \\
\text { \#MeQuedoEnCasa https://t.co/xxxxxxxxxx }\end{array}$ & 101 & 117 & Neutro \\
\hline $\begin{array}{l}\text { Fallece otro compañero por el covid-19. Nuestro más sentido pésame a la familia. D.E.P. } \\
\text { \#COVID19 } \\
\text { \#MeQuedoEnCasa https://t.co/xxxxxxxxxx }\end{array}$ & 91 & 154 & Positivo \\
\hline $\begin{array}{l}\text { TIENE QUE DESAPARECER. } \\
\text { Este presidente, ha llamado a nuestro \#Ejército (ayer) que es un gasto SUPERFLUO } \\
\text { A parte, \#EquiparaciónSalarial } \\
\text { La gente está muriendo por no actuar en Enero } \\
\text { La corrupción del \#PSOE. } 2 \\
\text { \#GobiernoCriminal } \\
\text { \#PedroSanchezDimision } \\
\text { \#MeQuedoEnCasa } \\
\text { \#VOX }{ }_{\text {https://t.co/xxxxxxxxxx }}\end{array}$ & 89 & 126 & Negativo \\
\hline
\end{tabular}

PSOE: Partido Socialista Obrero Español; Vox: [un partido político de España]. 
Tabla 3 Recuento de difusión de los tuits según la cantidad de retuits y por polaridad

\begin{tabular}{lllllll}
\hline \multicolumn{1}{c}{ Difusión de tuits } & \multicolumn{2}{c}{ Positivo } & \multicolumn{2}{c}{ Neutro } & \multicolumn{2}{c}{ Negativo } \\
\cline { 2 - 7 } & Frecuencia & Porcentaje (\%) & Frecuencia & Porcentaje (\%) & Frecuencia & Porcentaje (\%) \\
\hline Tienen más de 10 retuits & 41 & 2,3 & 62 & 3,2 & 9 & 3,7 \\
Tienen entre 1 y 10 retuits & 574 & 32 & 557 & 28,8 & 48 & 19,7 \\
No tienen retuits & 1177 & 65,7 & 1316 & 68 & 187 & 76,6 \\
Totales & 1792 & 100 & 1935 & 100 & 244 & 100 \\
\hline
\end{tabular}

española, hasta cuestiones relativas a la toma de conciencia social (COVID-19 e infancia, por ejemplo) o la expresión del pésame por la muerte de un compañero, pasando por la crítica política. De todos modos, nos parece relevante reseñar que las estrategias de eco (retuiteo y menciones) no constituyen la tendencia de la muestra, sino más bien una excepción. El promedio de FAV recibido por los tuits es escaso: cercano a los 2 (2,2 para los positivos, 1,9 para los neutros y 1,6 para los negativos). La Tabla 3 refleja el grado de redifusión de los mensajes.

Como vemos, en su mayoría, los mensajes no son retuiteados, lo que nos lleva a pensar que buena parte de la vinculación en torno a esta etiqueta no se corresponde con una comunidad densa, o redes de soporte y apoyo, sino más bien con una entidad de agrupación temporal en relación con un hecho concreto.

\section{Origen de los tuits: características de las cuentas}

¿Qué características muestran las cuentas que tuitearon? La observación de los datos nos revela que bajo el hashtag \#MeQuedoEnCasa se organizó una comunidad discursiva muy heterogénea, con propiedades muy dispares. Hay una diferencia significativa entre la media de seguidores de las cuentas con tuits positivos, 3128 seguidores en promedio por cuenta, y las cuentas con tuits negativos, 1609 seguidores por cuenta.

Para establecer el contraste entre las cuentas con más y menos seguidores, se implementó este procedimiento: en primer lugar, se tomó como muestra de partida el conjunto de tuits iniciativos, es decir, en los casos de retuits, solo se consideró la contribución que se producía inicialmente. En segundo lugar, se procedió a ordenar de mayor a menor la cantidad de seguidores que tenían esas cuentas. En tercer lugar, se seleccionaron 100 tuits de cuentas con mayor cantidad de seguidores y 100 tuits de la parte inferior de la tabla, es decir, aquellas que tenían menor cantidad de seguidores. Por último, se calcularon los datos relativos a media y mediana de ambos grupos. La Tabla 4 refleja estos datos.

Tabla 4 Media y mediana de la cantidad de seguidores de las cuentas que publicaron tuits iniciales

\begin{tabular}{lllll}
\hline \multirow{2}{*}{$\begin{array}{c}\text { Polaridad } \\
\text { de los }\end{array}$} & \multicolumn{4}{c}{ Cantidad de seguidores } \\
\cline { 2 - 5 } tuits & Media & Mediana & Media & Media mínima \\
\hline Positivo & 3128 & 450 & 67472 & 7 \\
Neutro & 3081 & 473 & 73982 & 4 \\
Negativo & 1609 & 456 & 6655 & 41 \\
\hline
\end{tabular}

La media de seguidores es significativamente más alta en los tuits positivos y neutros que en los negativos. Las cuentas con más número de seguidores y, por lo tanto, con más influencia, publicaron más tuits positivos o neutros: 31 mensajes de cuentas oficiales corresponden a la polaridad positiva, 42 tuits a la neutra y solo 4 a la negativa. Estos cuatro tuits oficiales con polaridad negativa son, fundamentalmente, mensajes en los que se denuncian incumplimientos del confinamiento.

Desde el punto de vista de la teoría de la valoración, la naturaleza de la cuenta que origina el mensaje se relaciona de forma directa con el dominio semántico del compromiso. Como sostiene Kaplan (2004), 
esta categoría asume una dimensión intersubjetiva, en la que los enunciadores se conciben como sujetos sociales. Es decir, desde esta perspectiva, "la modalidad no se concibe bajo una óptica epistémica sino heteroglósica” (Kaplan, 2004, p. 70): el compromiso no se refleja únicamente en las palabras, sino también en la propia reputación de la fuente. En el caso concreto de los retuits, por ejemplo, el compromiso se concibe como una atribución, categoría correspondiente a la extravocalización, dentro de la tipología que sintetiza Kaplan (2004, p. 70).

\section{Frecuencias léxicas}

Para el cálculo de las frecuencias léxicas se empleó la herramienta de análisis de corpus AntConc. Una vez eliminadas las stop words, o palabras de uso frecuente en español, sin contenido léxico explícito, el corpus quedó reducido a una extensión de 163 651 unidades, con una variación de 21356 palabras diferentes. Dejando al margen las palabras contenidas en la etiqueta analizada \#MeQuedoEnCasa, las 15 unidades (palabras o colocaciones) más frecuentes en el conjunto del corpus se recogen en la Figura 4.
¿Qué nos revelan estas frecuencias léxicas? Principalmente, que se organizan en torno a una serie de atributos, agrupados en campos semánticos, que funcionan como estrategias de encuadre léxico de la pandemia. Asimismo, nos dan cuenta de los conceptos en los que se focalizó el dominio de la gradación.

En la nube de palabras que se muestra en la Figura 5, se marcan en negro las dos palabras más frecuentes: "Covid" y "coronavirus". Alrededor de ellas, que funcionan como ejes centrales de la gráfica, establecemos una serie de marcos léxicos que se distinguen por colores. Destacamos particularmente cuatro: salud (salud y cuarentena), en color verde; colectividad (yo, gente, España), en color morado; ubicación espacial (casa, aquí), en color azul, y referencias temporales (día, cuarentena, confinamiento), en color amarillo.

En color rojo se han marcado las palabras relativas a campos semánticos emocionales, que funcionan como marcas valorativas actitudinales: "ánimo" y "sí. Los tamaños de las palabras responden a la frecuencia relativa de cada uno de los términos.

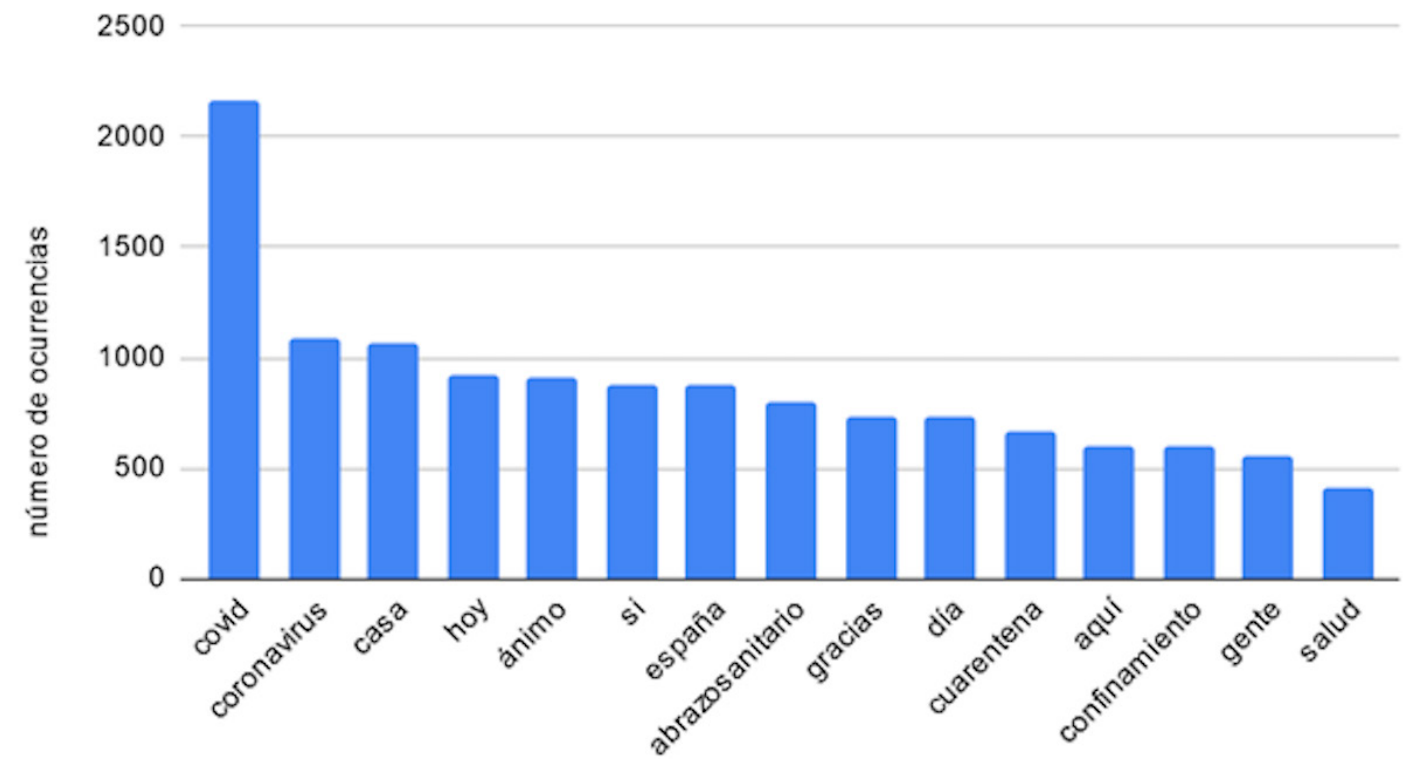

Figura 4 Palabras más frecuentes en la muestra total 


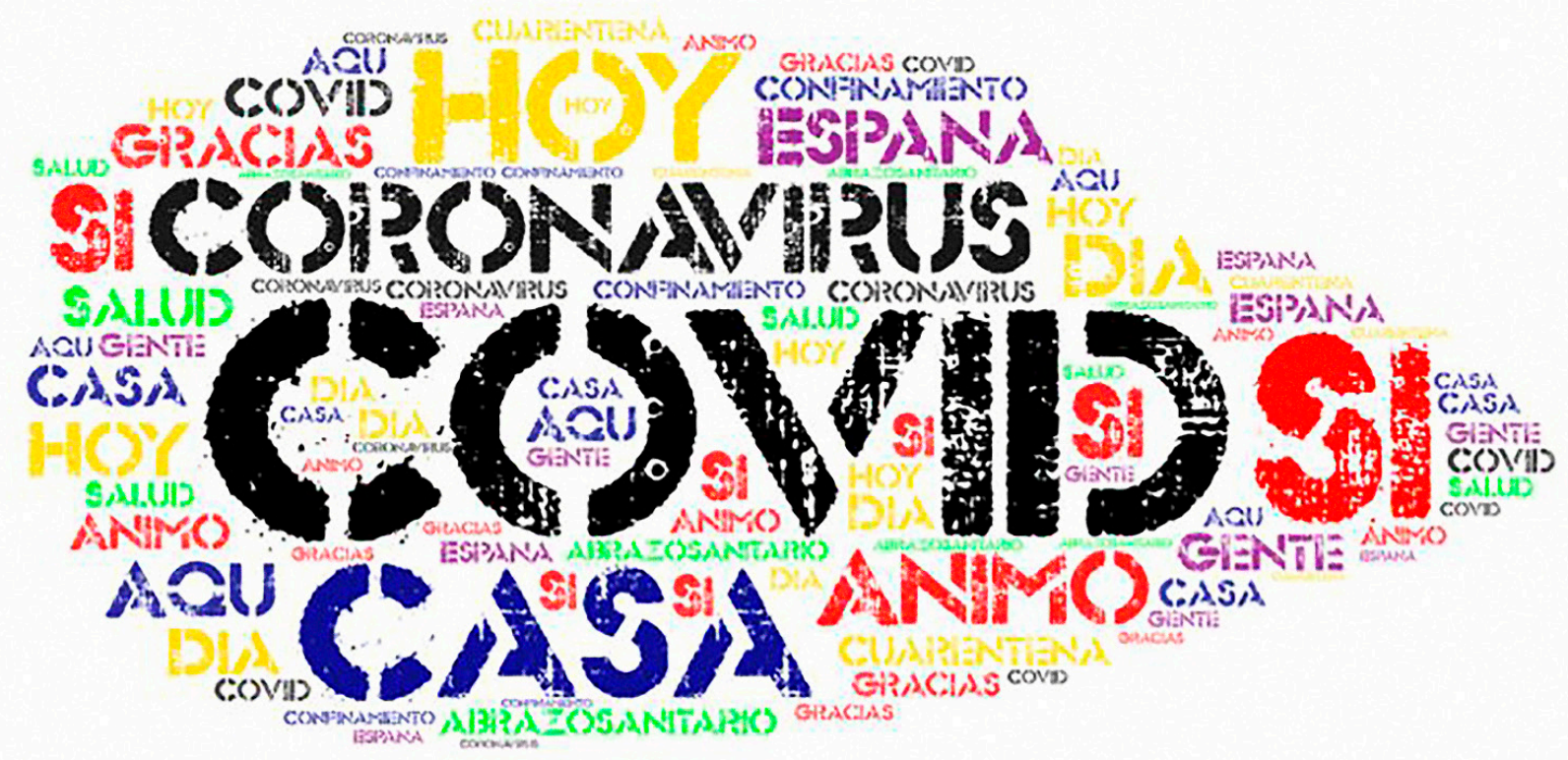

Figura 5 Nube de palabras más frecuentes en la muestra total

Si observamos detenidamente los resultados, podemos comprobar que el hashtag determina, en cierta manera, el encuadre que se hace de la enfermedad. De hecho, la relación con el motivo del encierro y la permanencia resulta evidente y así lo demuestran tanto la frecuencia de los términos "casa" y "aquî" como su coaparición en el estudio de las colocaciones.

También es importante la relación que se establece con el concepto de tiempo. La cuarentena se vivencia como un estado temporal, una característica del presente más inmediato, como queda justificado con la recurrencia de términos como "hoy" y "día”.

Llama también la atención el contraste entre la voluntad individual que manifiesta el hashtag ya hemos mencionado la presencia de la primera persona en su formulación- y el refuerzo de la identidad colectiva: la repetición de los términos "gente" y "España” se orienta hacia la experiencia grupal del confinamiento. De alguna manera, se estaría proyectando la correlación entre el individuo y el grupo: 'yo me quedo en casa por la gente, por España'.
Como no podía ser de otro modo, entre las palabras frecuentes también se ubican términos relativos a la salud, aunque resulta llamativo que estos tengan una reiteración menor.

Especialmente interesante nos parece una de las palabras frecuentes, "cuarentena”, que, de alguna manera, sintetiza el marco semántico del hashtag. La cuarentena es un encierro temporal por causas de salud para prevenir contagios grupales. De hecho, la propia etiqueta, \#MeQuedoEnCasa, vendría a ser una paráfrasis de la idea de cuarentena. Sin embargo, el modo en que se ha construido esta paráfrasis selecciona, de entre todas las posibles, una formulación que apela a lo emocional y a la responsabilidad individual. Sobre estos dos valores se construye precisamente el marco de encuadre.

Resulta en particular relevante que los vocablos relativos al ámbito de las emociones tengan una evidente carga positiva. El más frecuente es “ánimo", que establece un fuerte vínculo con la idea de colectividad. De hecho, cabe mencionar que, aunque hayamos organizado los términos frecuentes por campos semánticos, entre todos ellos existe una evidente vinculación. 
Si en el cálculo de las frecuencias léxicas aplicamos la variable de polaridad emocional en relación con la lista de las 15 palabras más usadas, ordenadas de más a menos frecuente, observamos los resultados desglosados en la Tabla 5.

Tabla 5 Palabras más frecuentes en los tuits según polaridad emocional

\begin{tabular}{|c|c|c|c|}
\hline & Positivos & Neutros & Negativos \\
\hline 1 & COVID & COVID & COVID \\
\hline 2 & gracias & ánimo & gente \\
\hline 3 & casa & coronavirus & gobierno criminal \\
\hline 4 & hoy & España & sí \\
\hline 5 & coronavirus & sí & parte \\
\hline 6 & ánimo & casa & PSOE \\
\hline 7 & día & hoy & muriendo \\
\hline 8 & cuarentena & dan & presidente \\
\hline 9 & sí & cuarentena & Actuar Vox \\
\hline 10 & familia & días & Vox \\
\hline 11 & aquí & aplauso & ayer \\
\hline 12 & momentos & sobra & corrupción \\
\hline 13 & homenaje & cántabros & desaparecer \\
\hline 14 & mejor & Racing & ejército \\
\hline 15 & confinamiento & así & gasto \\
\hline
\end{tabular}

Entre las quince palabras frecuentes de los tuits positivos, encontramos términos como "mejor", con una evidente orientación positiva desde el punto de vista evaluativo, que, además, funcionan como marcas de gradación, al intensificar la fuerza de las categorizaciones semánticas.

En relación con la lista de frecuencias del conjunto de la muestra, en los positivos suben puestos los conceptos relacionados con la "familia" y se refuerza la idea de colectividad, mediante la palabra "homenaje". El primero remite a una cuestión de solidaridad de grupo; la idea de colectividad se marca en la muestra global, pero en los tuits positivos se hace de forma más explícita, a través de la referencia a la familia. La noción de "familia" arrastra muchas connotaciones positivas, que sirven para reforzar la sensación de vivencia compartida y de solidaridad.
No olvidemos que la gradación se manifiesta en dos niveles: por un lado, la fuerza; por otro lado, el foco. La fuerza hace referencia a la intensificación, mientras que el foco sirve para indicar el estatus central de un valor representado. Según el modelo de Moreno Ortiz (2019), la gradación se corresponde con "el uso de cuantificadores y otros medios lingüísticos para definir la intensidad de los distintos juicios de valor" (p. 45) — tal sería el caso de la palabra "mejor"-; y el foco se representa a través de los elementos o atributos que se relacionan con los frames — tal sería el caso de "familia" -

Si comparamos las columnas de frecuencias léxicas de los tuits positivos y neutros, podemos comprobar que ambas son muy parecidas. Llama la atención que, entre los tuits positivos, la palabra "ánimo" no se encuentre entre las diez más frecuentes, y que, sin embargo, sea la segunda entre los que se categorizan como neutros. De alguna manera, el término "ánimo" implica asumir un punto de partida negativo que es necesario compensar. En el resto de unidades hay bastante coincidencia. Ahora bien, entre los tuits neutros se encuentran bastantes ejemplos de aportaciones que tienen que ver con temas como la suspensión de partidos de fútbol. Particularmente interesante, por anecdóticos, por ejemplo, resultan el conjunto de mensajes que tratan sobre la situación del Racing de Santander (equipo de futbol de Cantabria, España) en la liga.

Si nos centramos en la frecuencia léxica de los tuits con polaridad negativa, vemos que emergen palabras reiteradas muy distintas a las que encontrábamos en las otras dos categorías. Para empezar, tenemos el campo semántico de la política, con palabras como "gobierno" y evaluaciones de este concepto a través del término "criminal". Además, hallamos referencias frecuentes al partido en el gobierno (PSOE), al tiempo que se repite la palabra "presidente" como responsable de las decisiones que han producido el confinamiento. También se identifican bastantes términos relativos al ámbito de la guerra, que remite a uno de los marcos que más se han reiterado en la conversación digital 


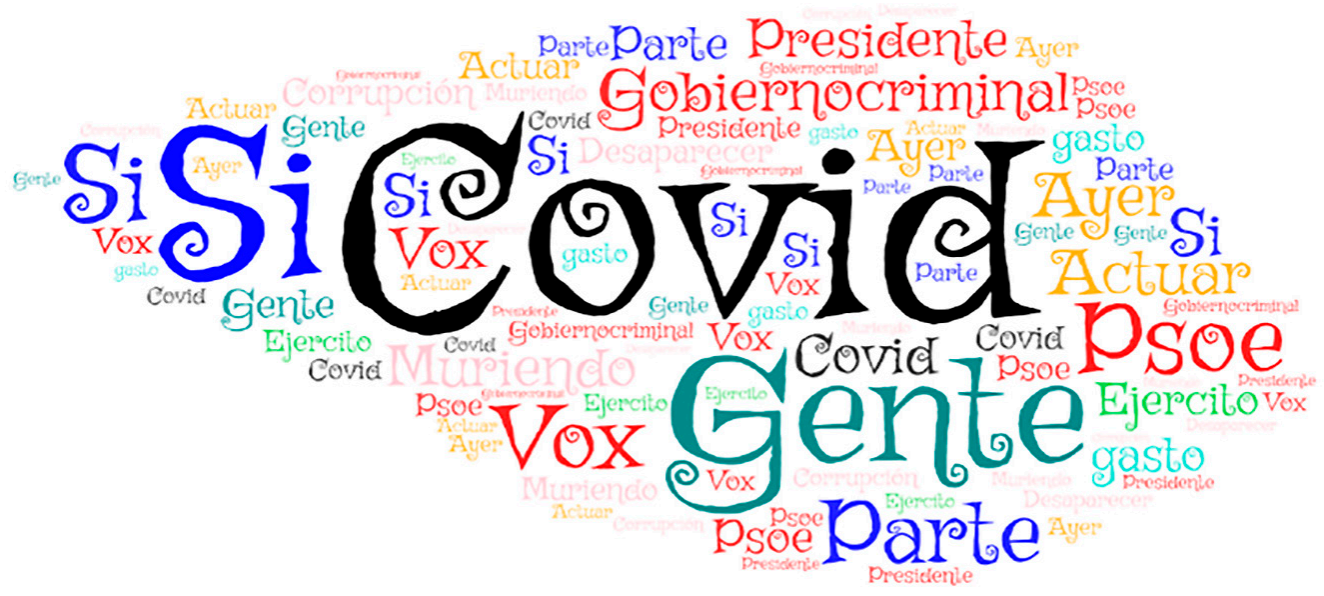

Figura 6 Nube de palabras más frecuentes en los tuits de polaridad negativa

sobre la Covid-19: la metáfora bélica. En este caso, sin embargo, el término "ejército" no se usa de forma metafórica, sino que alude al papel que las fuerzas armadas desempeñan durante el estado de alarma.

Hay que mencionar, además, la carga negativa de otras dos palabras frecuentes: "corrupción" y "muriendo". Se muestra una visión dramática de la salud, que se expresa de forma indirecta a través de su pérdida con la muerte. La palabra "corrupción” también denota una concepción negativa de la política.

Es reseñable que la segunda palabra en frecuencia de los tuits negativos sea "gente". Deja claro que estos mensajes manifiestan una clara orientación hacia la movilización colectiva. La nube de palabras en la Figura 6 representa gráficamente estos resultados.

La importancia de la movilización en el conjunto de los tuits negativos se confirma con el hecho de que entre la lista de palabras frecuentes encontramos el verbo "actuar". En el resto de los tuits, los verbos más usados son "estar", "ser” y "hacer”. Estas recurrencias demuestran que el confinamiento se vive como una experiencia de permanencia - ser y estar-, que se necesita llenar de actividades - hacer - con las que ocupar el tiempo. Esta orientación a la acción se verá en relación con el análisis cualitativo, por ejemplo, de los emojis, en el siguiente apartado.

\section{Los emojis y otros recursos visuales en los tuits}

Los emojis son recursos icónicos que se emplean en la interacción digital escrita, para transmitir parte del componente evaluativo que en la interacción cara a cara se vehicula mediante otros recursos no verbales. En tal sentido, codifican buena parte del contenido valorativo y emocional de estos intercambios.

En nuestra muestra, cerca de la mitad de los tuits, concretamente el $42 \%$, contienen algún emoji. Algunos de ellos aparecen de forma puntual y otros de manera frecuente. A continuación, presentamos los datos de la submuestra de 4071 tuits que contienen emojis.

El emoji más recurrente es el de la bandera española ( $\square)$, que se encuentra en 494 tuits, es decir, en el $12 \%$ del total de los mensajes que tienen estos elementos expresivos. Por su parte, los emojis del aplauso ( $)$ y de la fuerza/ánimo (b) aparecen, cada uno, en el 9 y el $8 \%$ de los tuits de esta submuestra, respectivamente.

Algunos emojis llaman la atención por su ausencia. Precisamente, por la temática del hashtag, era de esperar que aparecieran emojis que representaran 
casas. Sin embargo, el emoji de la casa, en sus dos versiones (con $\mathrm{p}$ o sin jardín . en un $5 \%$ de los tuits; lo mismo sucede con el emoji del virus (.) que se halla únicamente en el $4 \%$ de estos tuits. En ambas ocasiones encontramos un contraste entre las palabras más frecuentes, entre las que estaban "casa”, "CoviD” o "coronovirus", y los emojis: los usuarios optaron de forma más habitual por emojis con otros contenidos semánticos.

Además, observamos otras marcas propias del discurso digital para vehicular la expresividad, como las siglas "XD" para indicar risa, que aparecen 29 veces; el emoticono de la risa en diferentes versiones, :) o ;-), con 13 ocurrencias, o su contrario, :(, que está 2 veces. También son especialmente relevantes, desde el punto de vista expresivo, las publicaciones que emplean los caracteres del teclado para generar recursos retóricos visuales, como los ejemplos que se muestran a continuación, en los que se trata de dibujar una casa o un conejo con un cartel que incluye un hashtag con la recomendación de lavarse las manos.
Ejemplo 5

$$
\text { Yo, \#MeQuedoEnCasa }
$$

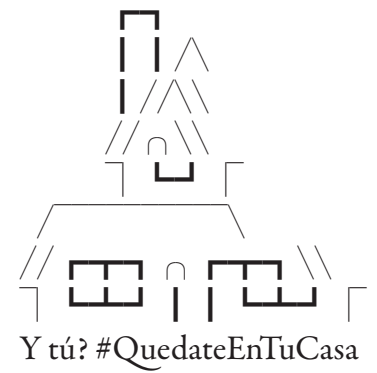

Ejemplo 6

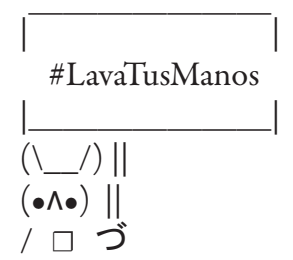

¡Dale RT para todos y todas lo hagan!

\#covid-19 \#MeQuedoEnCasa

En la Figura 7 reflejamos una panorámica del total de los emojis empleados en la muestra

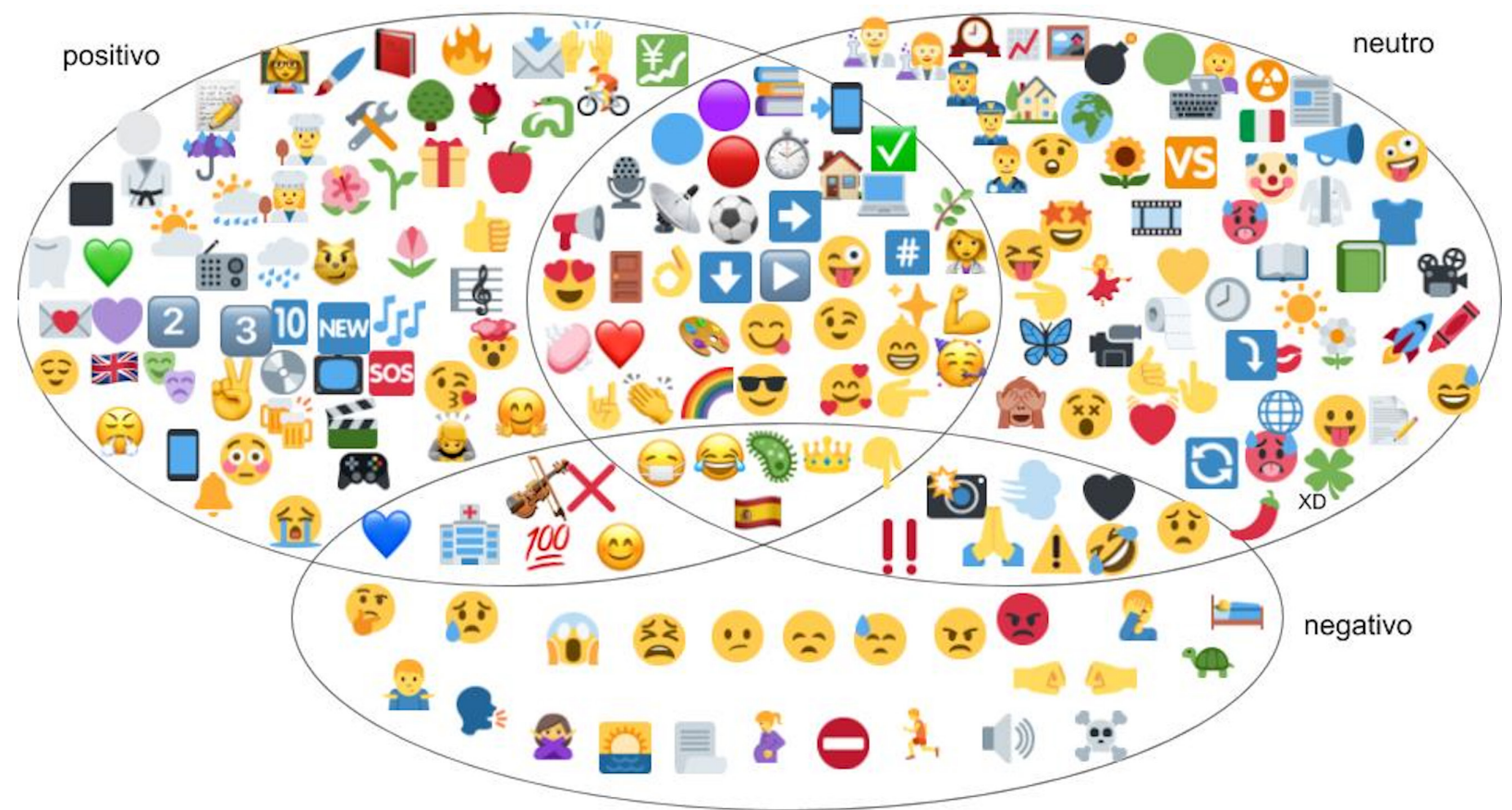

Figura 7 Nube de los emojis presentes en la submuestra de 600 tuits según su polaridad 
aleatoria de 600 tuits representativos de nuestro corpus. Se han organizado a modo de intersección de conjunto, de manera que en el centro se sitúan aquellos presentes en todas las polaridades emocionales, y en cada subconjunto, los específicos de cada una de ellas.

Podemos ver que la naturaleza de los emojis en cada una de las secciones es muy diferente. Para este análisis, partimos de la clasificación reflejada en la página del Consorcio Unicode, ${ }^{2}$ entidad sin ánimo de lucro que vela por la estandarización de los emojis. Los tuits negativos presentan más emojis de carácter emocional, es decir, relativos a la categoría "caritas y emoción", mientras que los positivos y neutros se relacionan con emojis figurativos, que representan objetos y realidades de la vida cotidiana.

Siguiendo la distinción propuesta por Bai et al. (2019), que diferencia dos grandes grupos de funciones para los emojis, los emocionales y los semánticos, la función emocional está más presente en los tuits negativos, y la semántica, en los positivos. Esto nos estaría dando la pista de que los emojis funcionan en la muestra evaluada de un modo más referencial que valorativo.

Los siguientes ejemplos ilustran este contraste:

\section{Ejemplo 7}

$\because \because \because$ G or si no hubieran echo lo que hicieron con nuestra sanidad... hoy en día no tendríamos más de mil muertos $=$

Ejemplo 8

Hoy hace en València una mañana muy de La Traviata. \%.... 96

Sin embargo, conviene recordar las conclusiones a las que han llegado algunos estudios sobre los emojis, que afirman que aquellos con connotaciones emocionales positivas resultan más frecuentes

2 https://home.unicode.org/ que los que presentan valores negativos (Prada et al., 2018). Este parece ser el caso de nuestra muestra, ya que, de alguna manera, el empleo de emojis tiene, por sí mismo, una función valorativa. Así, según Yus (2014), los emojis y otros recursos creativos para la deformación expresiva del texto constituyen estrategias discursivas empleadas no solo para dirigir al destinatario en la interpretación prevista del mensaje, sino también para transmitir las actitudes proposicionales subyacentes y los sentimientos y las emociones asociados al mensaje. Los emojis portan, en sí mismos, su presunción de relevancia y son empleados para manifestar los matices de experiencias emocionales específicas que difícilmente pueden ser codificadas mediante el léxico afectivo. Podemos ilustrar este aspecto con el Ejemplo.

\section{Ejemplo 9}

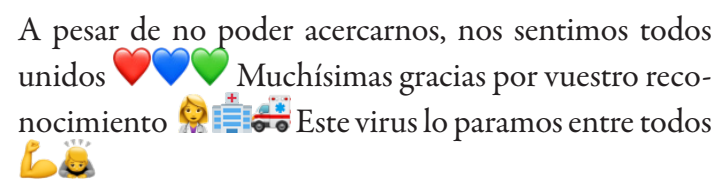

Siguiendo a Danesi (2016), podemos afirmar que una de las funciones fundamentales de los emojis es emular recursos no verbales en la comunicación oral, principalmente gestos emblemáticos. Tal sería el caso del Ejemplo.

Ejemplo 10

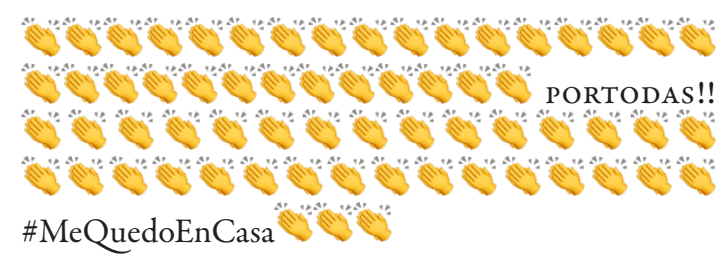

Especialmente interesantes son también los emojis que se usan para contradecir el contenido explícito de un enunciado, es decir, para marcar ironía. A ellos podrían atribuírseles valores relacionados con el compromiso, ya que tanto la ironía como la broma son procesos que arrancan de la heteroglosia, en cuanto implican cierta expansión o contracción diaglósica de atribución o refutación 
del contenido proposicional del enunciado al que se acompaña. Pongamos, por caso, los Ejemplos.

Ejemplo 11

Tengo bizcocho y no lo comparto!

Ejemplo 12

No sé qué chándal ponerme

\section{Otros aspectos del encuadre discursivo}

Además del estudio cuantitativo del corpus extenso, hemos procedido a un análisis cualitativo de la muestra seleccionada de 600 tuits. Para ello, aplicamos el modelo propuesto por Gallardo Paúls (2014), que distingue tres tipos fundamentales de encuadre: el encuadre a nivel enunciativo, el encuadre a nivel textual y el encuadre a nivel interactivo.

El encuadre a nivel enunciativo se organiza en torno a las diferentes estrategias léxicas, que ya han sido estudiadas en el análisis lexicométrico, pero también con aspectos de las estrategias predicativas y de las estrategias interaccionales.

Desde el punto de vista predicativo, es decir, del entramado de relaciones léxicas, encontramos algunos procesos interesantes, como las relaciones de inclusión del individuo en la colectividad, o las relaciones de metonimia entre el confinamiento y distintos aspectos vinculados con la permanencia en casa. La propia casa aparece como metonimia de la situación y las actividades que hacemos en casa como concreción del confinamiento.

En relación con la estrategia intencional, como cabía esperar, predominan los actos de habla expresivos, entre ellos los agradecimientos, las manifestaciones de ánimo en los tuits positivos y la denuncia en los tuits negativos. El ataque al oponente, en este caso personificado en el "gobierno", también aparece de forma recurrente en los tuits negativos. Los tuits clasificados como neutros tienden a presentar más actos de habla representativos, es decir, muestran qué se hace durante el confinamiento o qué se podría hacer.

En lo que concierne al encuadre textual, llama la atención que los tuits positivos son más narrativos o expositivos, mientras que las secuencias argumentativas están más presentes en los tuits negativos.

Por su parte, el encuadre interactivo descansa, en gran medida, en el juego de sucesión de diferentes hashtags, con los que se combina el que nos ha ocupado en este trabajo, como en el Ejemplo.

Ejemplo 13

Los ratitos de 11 a 12 me dan vida $\because$ \#
(1) \#CuarentenaPositiva \#MeQuedoEnCasa
\#docentescomprometidos

\section{Discusión y conclusiones}

El análisis de la conversación en torno al hashtag \#MeQuedoEnCasa nos aporta algunas claves para comprender el encuadre discursivo que se hizo del confinamiento domiciliario en los primeros días del estado de alarma en España. Como parecía presumible, dada la propia formulación del hashtag, detectamos cierta tendencia hacía la polaridad emocional positiva. La teoría de la valoración nos ha ofrecido un marco teórico amplio y suficientemente flexible para analizar de forma crítica los procedimientos semióticos en los que se concreta la función evaluativa: tanto aspectos lingüísticos como multimodales.

El análisis empírico que hemos realizado nos permite identificar ciertas tendencias. Entre ellas: 1) que los tuits más retuiteados mantuvieron una orientación emocional positiva; 2) que las cuentas oficiales o cuentas más influyentes también inclinaron su producción discursiva hacia la polaridad positiva, y 3) que los tuits manifestaron una difusión baja, es decir, circularon en una comunidad poco cohesionada.

Desde el punto de vista léxico, las palabras frecuentes resultaron muy similares en los tuits positivos 
y neutros, mientras que fueron más divergentes en los tuits negativos. De tal suerte que podemos proponer la siguiente síntesis del frame o encuadre sobre el que orbita el hashtag en relación con sus palabras más usadas:

Nosotros - yo + gente- (colectividad) nos animamos (ánimo/gracias) para quedarnos en casa (lugar) ahora (día, hoy) por la salud.

Estas frecuencias podrían dar cuenta de la centralidad o protipicidad de ciertos conceptos que habrían de someterse a prueba para determinar hasta qué punto obedecen a la disponibilidad cognitiva o a la presión inferencial del grupo social.

El análisis de los emojis también expuso la orientación positiva de la conversación virtual y arrojó alguna luz sobre las principales temáticas abordadas en la muestra. Los emojis más frecuentes indican fuerza, ánimo u otras expresiones relacionadas con la manifestación de emociones y la gradación.

La etiqueta \#MeQuedoEnCasa comienza como una suerte de arenga para la toma de conciencia de la importancia del distanciamiento físico como medida preventiva contra la expansión del virus, al mismo tiempo que funciona como una marca sobre la cual agrupar diferentes iniciativas que ayuden a los ciudadanos en este esfuerzo. La tendencia positiva se acentúa en aquellos mensajes con una orientación interpersonal, mientras que desciende cuando se abordan temas políticos. Esta oposición revela la construcción de cierta identidad comunitaria (Tajfel, 1981), que marca positivamente los mensajes del endogrupo (la comunidad) respecto a aquellos del exogrupo ("los otros", generalmente, los políticos). Esta construcción identitaria se afianza, además, mediante el empleo de un léxico frecuente común relacionado con el campo semántico de la covid-19.

Por todo ello, podemos concluir que el hashtag \#MeQuedoEnCasa ha funcionado como una marca de identidad social, que ha servido para fomentar la responsabilidad del individuo desde valores positivos. Los actos de habla más abundantes de nuestro corpus se corresponden con la enunciación de consejos y actos expresivos de ánimo. La comunidad discursiva que participa de esta etiqueta despliega una actitud responsable y positiva hacia el confinamiento, desde las funciones ideacional, interpersonal y textual.

Desde la foto fija de la conversación digital surgida en torno al hashtag \#MeQuedoEnCasa, durante el principio del confinamiento domiciliario por la crisis de la covid-19, este trabajo abre un camino para futuras investigaciones que aporten más información sobre el papel de estas plataformas en la generación de marcos interpretativos. Resultaría interesante comparar los resultados de este estudio con los proporcionados por la exploración de otras etiquetas u otros cortes temporales. Asimismo, sería de interés evaluar la progresión que esta conversación digital ha asumido a lo largo del tiempo y la manera en que se ha ido modulando el enmarque interpretativo. A falta de este estudio diacrónico, los resultados no permiten establecer predicciones sobre el progreso del estado de opinión a lo largo de la crisis sanitaria o el modo en que convivió, en las redes sociales, con otras etiquetas cuya polaridad positiva fuera menos evidente.

De igual modo, cabría contrastar las conclusiones de este estudio con el análisis de otras redes de difusión: Twitter ${ }^{\circ}$ es un espacio público y abierto $\mathrm{y}$, presumiblemente, el posicionamiento discursivo de los sujetos debiera ser distinto del asumido en otras redes sociales privadas como, por ejemplo, WhatsApp. Hemos de reconocer que la polaridad positiva identificada en nuestro estudio no refleja, necesariamente, el acuerdo social con las medidas de aislamiento, sino la manera en que este se materializa discursivamente en Twitter ${ }^{\circ}$.

\section{Referencias}

Acosta, M. y Nevache, C. (2020). La conversación digital en torno al hashtag \#RespetoAlDolorDeMadre en Panamá. Dígitos: Revista de Comunicación Digital, (6), 13-30. https:// doi.org/10.7203/rd.v1i6.171 
Ardèvol-Abreu, A. (2015). Framing o teoría del encuadre en comunicación. Orígenes, desarrollo y panorama actual en España. Revista Latina de Comunicación Social, (70), 423-450. https://doi.org/10.4185/ RLCS-2015-1053

Arroyas Langa, E., Martínez Martínez, H. y Berná, C. (2018). Twitter como espacio alternativo a la esfera política institucional. Análisis retórico de las estrategias discursivas de Podemos durante la moción de censura contra Rajoy. En J. Segarra- Saavedra, T. HidalgoMarí y R. Rodríguez-Ferrándiz (Coords.), Actas de las Jornadas Cientificas Internacionales sobre Análisis del discurso en un entorno transmedia (pp. 85-94). Universidad de Alicante, Alicante. https://doi. org/10.14198/MEDCOM/2017/11_cmd

Bai, Q., Dan, Q., Mu, Z. y Yang, M. (2019). A systematic review of emoji: Current research and future perspectives. Frontiers in Psychology, 10, 2221. https:// doi.org/10.3389/fpsyg.2019.02221

Cantamutto, L., Vela Delfa, C. y Boisselier, L. (2015), Comunicación Digital : Corpus del Español (CoDiCE). http://codice.aplicacionesonline.com.ar/

Cautín-Epifani, V. (2015). Poder virtual y formas de tratamiento en el discurso mediado por computadora: exploración en una red comunicativa virtual. Forma y Función, 28(1), 55-78. https://doi. org/10.15446/fyf.v28n1.51971

Danesi, M. (2016). The semiotics of emoji. The rise of visual language in the age of the internet. Bloomsbury Publishing.

Entman, R. (1993). Framing: Toward clarification of a fractured paradigm. Journal of Communication, 43(4), 51-58. https://doi.org/10.1111/j.1460-2466.1993. tb01304.x

Entman, R. (2008). Media framing biases and political power: Explaining slant in news of Campaign 2008. Journalism, 11(4), 389-408. https://doi. org/10.1177/1464884910367587

Epsilon Technologies (2020). Informe gran consumo de redes durante la crisis de COVID-19. https://www.epsilontec.com/clickfunnels/

Gallardo Paúls, B. (2014). Usos politicos del lenguaje. Un discurso paradójico. Anthropos.

Kaplan, N. (2004). Nuevos desarrollos en el estudio de la evaluación en el lenguaje: la teoría de la valoración. Boletín de Lingüistica, 22, 52-78.

Larrondo, A., Morales-i-Gras, J. y Orbegozo-Terradillos, J. (2019). Feminist hashtag activism in Spain: Measuring the degree of politicisation of online discourse on \#YoSíTeCreo, \#HermanaYoSíTeCreo, \#Cuéntalo y \#NoEstásSola. Comunication \& Society, 32(4), 207 221. https://doi.org/10.15581/003.32.4.207-221

McCombs, M. (2006). Estableciendo la agenda. El impacto de los medios en la opinión pública y en el conocimiento. Paidós.

Martin, J. R. y White, P. R. (2003). The language of evaluation. Palgrave Macmillan.

Molpeceres Arnáiz, S. y Filardo Llamas, L. (2020). Llamamientos feministas en Twitter: ideología, identidad colectiva y reenmarcado de símbolos en la huelga del 8M y la manifestación contra la sentencia de "La Manada". Dígitos: Revista de Comunicación Digital, (6), 55-78. https://doi.org/10.7203/ rd.v1i6.181

Moreno Ortiz, A. (2019). Mi opinión cuenta: la expresión del sentimiento en la red. En Comunicación mediada por ordenador: la lengua, el discurso y la imagen (pp. 38-74). Cátedra.

Moscovici, S. (1961). El psicoanálisis, su imagen y su público. Huemul.

Moscovici, S. (1998). Las representaciones sociales y la comunicación pragmática. Polis, 1(2), 205-222.

Pérez-Dasilva, J. A., K. Meso-Ayerdi y T. Mendiguren-Galdospín. (2020). Fake news y coronavirus: detección de los principales actores y tendencias a través del análisis de las conversaciones en Twitter. El profesional de la información, 29(3) e290308. http:// www.elprofesionaldelainformacion.com/contenidos/2020/may/perez-meso-mendiguren.pdf

Prada, M., Rodrigues, D. L., Garrido, M. V., Lopes, D., Cavalheiro, B. y Gaspar, R. (2018). Motives, frequency and attitudes toward emoji and emoticon use. Telematics and Informatics, 35(7), 1925-1934. https://doi.org/10.1016/j.tele.2018.06.005

República Argentina, Boletín oficial (2020). Decreto 297/2020. Aislamiento social preventivo y obligatorio. 20 de marzo de 2020. https:// www.boletinoficial.gob.ar/detalleAviso/ primera/227042/20200320

Tajfel, H. (1981). Human groups \& social categories. Studies in social psychilogy. Cambridge University Press.

Van Gorp, B. (2007). The constructionist approach to framing: Bringing culture back. Journal of Communication, 57(1), 60-78. https://doi. org/10.1111/j.0021-9916.2007.00329.x.

Vela, C. y Cantamutto, L. (2015). Problemas de recogida y fijación de muestras de discurso digital. Chimera, Romance Corpora and Linguistics Studies, 2, 131-155. 
White, P. (2004). The Appraisal website: The language of attitude, arguability and interpersonal positioning. https://www.grammatics.com/appraisal/

Yus, F. (2014). Not all emoticons are created equal. Linguagem em (Dis) curso, 14(3), 511-529. http:// dx.doi.org/10.1590/1982-4017-140304-0414
Zappavigna, M. (2011). Ambient affiliation: A linguistic perspectiveonTwitter.NewMediaぬSociety, 13(5),,788806. http://dx.doi.org/10.1177/1461444810385097

Zeifer, B. (2020). El hashtag contestatario: cuando los hashtag tienen efectos políticos. Digitos: Revista de Comunicación Digital, (6), 101-118. https://doi. org/10.7203/rd.v1i6.178

Cómo citar este artículo: Vela, C., Cantamutto, L., Núñez-Cansado, M. (2021). Análisis del hashtag \#MeQuedoEnCasa: la conversación digital por Twitter ante la emergencia producida por la Covid-19. Íkala, Revista de Lenguaje y Cultura, 26(2), 365-384. https://doi.org/10.17533/udea.ikala.v26n2a08 